ISSN: 2238-8052

\title{
A PRODUÇÃO CAPITALISTA DO ESPAÇO URBANO E O DIREITO À CIDADE EM NATAL/RN
}

THE CAPITALIST PRODUCTION OF URBAN SPACE AND RIGHT TO THE CITY IN NATAL/RN

\author{
Osmar Faustino OLIVEIRA ${ }^{1}$ \\ Manoel Raymundo CARVALHO NETO ${ }^{2}$ \\ José Geraldo PIMENTEL NETO ${ }^{3}$ \\ Flavio Antônio MIRANDA DE SOUZA ${ }^{4}$
}

Artigo recebido em 13/08/2018 e aceito em 17/12/2018

Palavras-chave:

Produção do Espaço; Estado;

Natal/RN
Key-words:

Production of Space;

State;

Natal/RN.

\section{R E S U M O}

A cidade do Natal é o principal centro de toda a movimentação financeira e de mercadorias, do Estado do Rio Grande do Norte-RN. Sendo assim, esta cidade apresenta uma complexidade de funções capazes de atender a todas as formas de necessidade da população urbana. 0 presente estudo objetivo descrever o processo capitalista da produção do espaço urbano, como também a questão do direito à cidade em Natal/RN. Como procedimento metodológico o trabalho se desenvolve através de uma pesquisa bibliográfica de caráter exploratório e análise de dados. Com os resultados nota-se que a construção Civil é um forte setor que emprega muita mão de obra em Natal. A quantidade de empregos formais em 2000 era de 9.282 e em 2015 sucede um aumento para 17.848 pessoas empregadas neste setor. 0 mercado imobiliário na capital do Rio Grande do Norte vem ganhando espaço e mercado. Houve expansão do mercado imobiliário em alguns bairros da cidade, enquanto outros estão esquecidos em detrimento de seu valor de especulação. Evidenciou-se que boa parcela da população mais carente, mora em situações precárias e sem saneamento, o que nos faz concluir que o Estado deveria rever as suas ações em favor da população, pois o direito à cidade é amplo e deve contemplar a todas as classes e não apenas para quem pode pagar.

\begin{abstract}
A B S T R A C T
The city of Natal is the main center of all the financial and merchandise movement, of the State of Rio Grande do Norte-RN. Thus, this city presents a complex of functions capable of attending to all forms of need of the urban population. Objective: This study aims to describe the capitalist process of production of urban space, as well as the issue of the right to the city in Natal / RN. Methodology: As a methodological procedure the work is developed through an exploratory bibliographic research and data analysis. Results: With the results it is noticed that the Civil construction is a strong sector that uses a lot of manpower in Natal. The number of formal jobs in 2000 was 9,282 and in 2015 there is an increase to 17,848 people employed in this sector. The real estate market in the
\end{abstract}

\footnotetext{
1 Economista. Mestrando em Desenvolvimento Urbano pela Universidade Federal de Pernambuco. Especialista em Mercado de Capitais pela Universidade Federal do Rio Grande do Norte. E-mail: osmarfaustino@yahoo.com.br.

2 Mestre em Gestão e Economia da Saúde pela Universidade Federal de Pernambuco (UFPE). Secretário no Programa de PósGraduação em Gerontologia do Centro de Ciências da Saúde da UFPE. E-mail: manoelneto.ufpe@gmail.com.

3 Realizando pós-doutorado junto à Pós-Graduação em Desenvolvimento Urbano da UFPE. Bacharel e Licenciado em Geografia. E-mail: gerageo@gmail.com.

4 Professor Titular do Departamento de Expressão Gráfica e Professor permanente do Programa de Pós-graduação em Desenvolvimento Urbano (MDU) da Universidade Federal de Pernambuco. E-mail: fdesouza67@gmail.com.
} 
capital of Rio Grande do Norte has been gaining space and market. There has been expansion of the real estate market in some neighborhoods of the city, while others are overlooked to the detriment of its value of speculation. Conclusion: It was evidenced that a good portion of the poorest population lives in precarious situations and without sanitation, which leads us to conclude that the State should review its actions in favor of the population, since the right to the city is broad and should contemplate the all classes and not just for those who can afford it.

\section{INTRODUÇÃO}

O presente trabalho tem como objetivo descrever o processo capitalista da produção do espaço urbano da cidade do Natal/RN, em suas áreas de subúrbio e os bairros nobres e turísticos, como também discutir a questão do direito à cidade em Natal/RN. Para isso, o presente artigo recorre a uma metodologia de pesquisa investigativa, observacional e de caráter bibliográfico sobre o tema pesquisado, utilizando-se de livros, revistas, artigos, banco de dados e endereços eletrônicos. 0 trabalho procura mostrar o processo de articulação entre Estado, o mercado e sociedade na produção do espaço urbano de Natal/RN, em busca e na promoção do direito à cidade.

A pesquisa procura fazer uma leitura socioespacial da produção do espaço urbano, do objeto de pesquisa, a cidade do Natal/RN, pelo cenário que emerge nos últimos anos, onde o capital imobiliário, tem determinado e modificado a cidade no que se diz respeito aos seus aspectos estruturais e espaciais como um todo, por ser o segmento da economia mais forte desta capital.

A cidade de Natal foi fundada em 1599, e passou a exercer uma função político de grande importância no contexto do estado, pois se tornou, desde então, o principal espaço de decisões da capitania do Rio Grande, assim como era chamado o Rio Grande do Norte (CLEMENTINO, et.al. 2015).

0 presente trabalho estruturou-se trazendo aspectos teóricos, econômicos, demográficos e sociais, divididos em tópicos até sua finalização com os registros bibliográficos.

\section{REFERENCIAL TEÓRICO}

Santos Júnior (2017) toma como ponto de partida o entendimento de que a moradia e o solo urbano são bens necessários para a nossa existência na cidade. São bens fundamentais para a nossa reprodução social na cidade. 0 problema fundamental na economia capitalista é que a moradia e o solo urbano são bens privados e mercadorias e, como mercadorias, são bens que podem ser vendidas e compradas. Por essa razão, o acesso à moradia e ao solo urbano passa a ser mediados pelas regras que definem o acesso e o uso da propriedade privada. E como qualquer mercadoria no capitalismo, a moradia e o solo urbano têm valor de uso e valor de troca. Assim, para entender a produção capitalista da cidade, é importante trazer para a discussão alguns elementos da teoria de valor em Marx, em especial a sua definição em torno do valor de uso e do valor de troca (HARVEY, 2005, p.144). 
Já Abramo (1995) traz uma discussão sobre a definição da urbanização que é considerada como uma trajetória com características, na qual o urbano exerce funções nas relações sociais de produção e nos mecanismos necessários à sua reprodução. Ou seja, a urbanização não é apenas o aumento da população, mas também um processo de interações econômicas e sociais.

A cidade do Natal é o centro de circulação do dinheiro e de mercadorias, no Estado do Rio Grande do Norte-RN. Sendo assim, esta cidade apresenta uma complexidade de funções capazes de atender a todas as formas de necessidade da população urbana. Ou seja, correspondem à cidade principal de uma região, as conexões de comando e coordenação de uma rede urbana que se destaca pelo tamanho populacional e da economia, como também pelo desempenho de funções complexas e diversificadas, multifuncionalidades que constituem relações econômicas com várias outras aglomerações. Então, a Região Metropolitana corresponde a uma amostra definida institucionalmente com finalidade, composição e limites determinados. Nem sempre corresponde ao fato metropolitano que deve ser observado através da existência dos fenômenos como a concentração, centralização, integração regional e transbordamento. A Aglomeração Metropolitana corresponde à marca de ocupação contínua ou descontínua diretamente polarizada por uma metrópole, onde se concentram as maiores atividades de fluxos e as maiores densidades de população e atividades, envolvendo municípios com variados níveis de integração (CLEMENTINO, et.al, 2007).

David Harvey (2012) em seu artigo "O direito a cidade" aponta que a urbanização desempenhou um papel decisivo na absorção de capitais excedentes em escala geográfica sempre crescente, mas ao preço do explosivo processo de destruição criativa que tem desapropriado as massas de qualquer direito à cidade. 0 planeta como lugar construído colide com o "planeta das favelas". 0 autor indaga se o processo de urbanização é realmente bom para a sociedade. Pois bem, há os pontos negativos, como ele mesmo (HARVEY, 2012) argumenta que a urbanização sempre foi um fenômeno do capitalismo, dependente do excedente dos capitalistas. E que a urbanização depende do produto excedente que eles visam ganhar. Mas, para isso, é preciso mão-de-obra barata, se na própria cidade as pessoas não aceitarem os salários impostos pelos capitalistas, estes iriam preferir contratar os imigrantes. Isso é bastante comum nas regiões metropolitanas, pois a população que reside em pequenas cidades vai à busca de oportunidades de emprego. Então, aceitam qualquer salário para trabalhar, pois no interior não há oportunidades de trabalho para estes indivíduos. Isto é o sistema capitalista, a busca pela mais-valia que como diria Marx gera uma favelização das cidades (HARVEY, 2013).

O processo de urbanização, como escreveu Ermínia Maricato, houve uma explosão urbana, em que o meio urbano brasileiro aumentou significativamente nos últimos anos. As pessoas estão migrando para o centro, ou seja, para a cidade. 0 processo de urbanização não está acontecendo apenas na atualidade, mas sim desde o século passado com o processo de industrialização, em que as pessoas deixaram de trabalhar no campo para se tornarem "urbanas", digamos assim. Hoje em dia com 
o processo de globalização, a urbanização vem crescendo no Brasil. As cidades que se encontram próximas as capitais dos países são chamadas de Regiões Metropolitanas.

Tal processo está conexo a um imenso movimento de edificação da cidade, sendo forçoso para o assentamento residencial da população bem como as suas necessidades de trabalho, abastecimento, transportes, saúde, energia, água e etc. ainda que a direção adotada pelo crescimento urbano não tenha replicado suficientemente a todas as necessidades, o território foi ocupado e foram arquitetadas as condições para viver nesse espaço. Sendo assim, todos os 138 milhões de moradores residem em cidades (MARICATO, 2001).

Já Lefebvre (2001), em seu livro "O Direito à Cidade”, em linhas, indica que o direito à cidade, se confunde com o próprio direito à vida, e por isso mesmo independe de seu reconhecimento como membro "natural" ou não de certo espaço. 0 autor reivindica uma integral cidadania a todos os habitantes de uma determinada cidade, seja ela qual for, sendo este reconhecimento formal ou não formal.

A conclusão é positiva, não somente porque os postulados do texto indicam a emergência da humanização, mas também, porque apontam de maneira geral a necessidade do direito à liberdade. Desta forma, o texto é recomendado a todos os interessados no ensino de urbanismo e áreas afins, já que compreender essas questões é de primeira importância, para uma formação apropriada (LEFEBVRE, 2001).

0 conceito de renda da terra urbana adverte o modo especulativo da formação do preço da terra urbana, pois como o preço da terra é constituído pela disputa entre os capitalistas pelo acesso aos efeitos úteis de aglomeração, esse preço pode variar de acordo com a magnitude da contestação. Portanto, num período de grande desenvolvimento econômico e urbano, a disputa pelas localizações induziria a um acréscimo do preço da terra, até daquelas com menos acesso às finalidades úteis de aglomeração, ou seja, as piores localizadas. A terra urbana ao lado com as edificações nela presentes teria um valor, como o valor de alguma mercadoria estaria determinado pelo tempo de trabalho socialmente necessário para produzi-lo. No caso da terra urbana, incluiríamos de avaliar dois valores, o primeiro o valor dos produtos em si como o valor das casas, das infraestruturas, dos prédios públicos etc. e o valor dado pela localização desse produto dentro da aglomeração. 0 espaço como força de produção, quanto produto adiante de todos os produtos, nos leva além da questão do preço da terra e seu retorno à renda, por exemplo, para a questão categórica de como a cidade é produzida, segundo que interesses e como essa produção é controlada pelos agentes capitalistas de forma a se conseguir o lucro (SILVA, 2012).

Os agentes produtores do espaço urbano são os proprietários fundiários, os proprietários dos meios de produção, o Estado, os promotores imobiliários e os grupos sociais subalternizados ausentes às regras da produção de mercado. Cremos que a assimilação desses distintos conjuntos de agentes, 
por distintos autores, se baseia em distinções localidades do mercado imobiliário, e em alguns casos em diferenças apenas de terminologia, muito mais que diferenças teóricas importantes (SILVA, 2012).

É bastante interessante compreender o valor da terra urbana, pois ela tem seu uso em que o dono da terra obtém o lucro. Geralmente as terras são vendidas ao capitalista, para que este construa loteamentos a fim de valorizar ainda mais o solo urbano e obter maiores lucros. Bem, pelo menos Natal experimentou tais acontecimentos. Em que uma indústria ou um setor se instala em determinado local e que causa um efeito de valorização do espaço. A construção civil em Natal empregou uma quantidade significativa de trabalhadores formais. Como mencionado, pela implantação de uma empresa ou uma indústria em um determinado local, valorizando assim a área. Tudo isso, gera impactos no valor da terra urbana, tornando-a atrativa para construir e lugar de moradia (SILVA, 2012).

O solo urbano compõe uma mercadoria muito disputada pelos agentes capitalistas que produzem a cidade. Por meio de suas ações, esses atuantes controlam, dirigem e dão significação ao crescimento e reestruturação do espaço urbano.

É formidável avaliar que o processo de expansão urbana resultante da incorporação de novos cortes territoriais à cidade provoca uma consecutiva redefinição dos usos do solo e uma reestruturação urbana. Neste tema, enquanto agente produtor do espaço urbano, o Estado assume o papel de grande autoridade. É ele o principal provedor de infraestrutura e serviços e institui o padrão lícito atinente à ocupação e uso do solo, intervindo de forma direta e indireta no desempenho dos demais agentes, como os incorporadores e construtores, por exemplo, (BARBOSA; COSTA, 2012).

$\mathrm{Na}$ sociedade capitalista todos os processos produtivos tendem a ser organizados na forma capitalista e neste sentido a produção do espaço construído não é uma exceção. A análise parte da suposição de que na indústria da construção se ampliam de modo pleno das relações capitalistas que ela se compõe sobre a contraposição do capital e do trabalho assalariado, e a acumulação é o principal motivo da produção. 0 desenvolvimento e propagação das relações capitalistas compõem um processo histórico e o capital em extensão privilegia em um primeiro momento as divisões que lhe são mais adequadas. A indústria da construção é um dos últimos setores em que o capital deve cobrir uma série de obstáculos para impor-se. 0 capital deve adaptar-se e expandir certas modalidades de intervenção que aparecem até mesmo quando a construção já trabalha como um setor capitalista. As peculiaridades da cumulação neste setor precisam acabar na concentração sobre a renda do solo urbano, até mesmo em um plano de abstração geral.

Há a necessidade de criar qualidades de questões apropriadas que requerem inferência ou que o Estado se torne comprador de espaço edificado indispensável para o desenho do capital já que não se localizam compradores espontâneos, ou que apareça um capital de circulação que quebre temporalmente as prestações na medida em que se consuma o valor das bem vendas a prazo. Todas estas ocorrências têm repercussões distintas no desenvolvimento e no funcionamento das rendas do solo urbano, sendo as relações capitalistas as que afeiçoam a produção do espaço edificado. 
O Construtor capitalista, o agente que governa a produção e o processo do espaço construído. Como o capitalista, que opera, ele é o retentor de capital e dos meios produção e trabalho, desencadeia, abre e faz rodar a fabricação e entrega o procedimento, ou seja, o produto finalizado para o consumo, retirando é claro, a mais-valia, que é o seu principal objetivo, sendo o motor da ação. Avaliamos que ele é responsável por fazer a terra disponível para a produção e facilitação desconhecer por enquanto, a divisão em segmentos de papéis que podem aparecer a partir desta conjuntura. Em relação articulações subsidiárias, as atividades urbanas, além disso, são tomadas com este caráter em que os processos são de acumulação de capital, o comércio e a indústria, ou são processos claramente de consumo final comercial, e com significação geral de um arcabouço numa totalidade capitalista como a habitação, o consumo como mais-valia, consumo e como elemento de reprodução da força de trabalho (GONZÁLEZ, 2010).

Falar de mercado e sociedade é bastante relevante, pois existe uma relação de articulação, em que o capitalista oferece o salário e o trabalhador a sua mão de obra. Para entender essa articulação, é bem interessante entender onde o Estado se encontra em tais relações.

Marx (1983) em suas análises sobre o Estado se dedicou mais em separar o idealismo filosófico de Hegel, perante da interpretação materialista do Estado como processo ativo, consciente e auxiliar da atual composição da sociedade. 0 Estado surge da contradição entre os interesses privados e os da sociedade. No entanto, o Estado tem de adquirir uma existência independente, para garantir o interesse comum, torna-se o lugar de um poder alienígena, por meio em que pode dominar os indivíduos e os grupos (HARVEY, 2005). 0 que Marx escreveu sobre o Estado e as relações trabalhistas entre trabalhadores e capitalistas acontecem até hoje. Digamos que Marx já previa o que iria acontecer nas gerações futuras.

O Estado tem origem da necessidade de manter incompatibilidades de classe sob controle, mas que também se origina no meio da luta de classes, pois é normalmente o Estado da classe economicamente administradora, que, por seus recursos, torna-se também a classe politicamente diretora, que, por seus recursos, e assim, obtém novos meios de dominar como também explorar as classes oprimidas. O Estado antigo era, antes de tudo, o Estado dos senhores de escravos, ou seja, servia para controlar os escravos, assim, como o Estado feudal era o órgão da nobreza para oprimir os servos camponeses, e o Estado representativo moderno é o instrumento para explorar a mão-de-obra assalariada pelo capital. Porém, acontecem momentos excêntricos quando classes adversas quase se igualam em forças em que o poder do Estado, como aparente mediador, adquire, naquele momento, esta independência em relação a ambas as classes (HARVEY, 2005).

É bastante interessante o que Harvey coloca sobre o papel do Estado na sociedade. Primeiro ele traz um contexto histórico, depois descreve o verdadeiro papel do estado na sociedade capitalista moderna. Ele age como intermeado dos conflitos de classes entre os capitalistas e os trabalhadores. 
"O Estado não é, pois, de forma alguma, um poder imposto à sociedade de fora para dentro; tampouco é lia realização da ideia moral ou lia imagem e realidade da razão", como afirma Hegel. E antes, um produto da sociedade num determinado estágio de desenvolvimento; é a revelação de que essa sociedade se envolveu numa irremediável contradição consigo mesma e que está dividida em antagonismos irreconciliáveis que não consegue exorcizar. No entanto, a fim de que esses antagonismos, essas classes com interesses econômicos conflitantes não se consumam e não afundem a sociedade numa luta infrutífera, um poder, aparentemente acima da sociedade, tem-se tornado necessário para moderar o conflito e mantê-lo dentro dos limites da "ordem". Este poder, surgido da sociedade, mas colocado acima dela e cada vez mais se alienando dela, é o Estado... Na medida em que o Estado surgiu da necessidade de conter os antagonismos de classe, mas também apareceu no interior dos conflitos entre elas, torna-se geralmente um Estado em que predomina a classe mais poderosa, a classe econômica dominante, a classe que, por seu intermédio, também se converte na classe politicamente dominante e adquire novos meios para a repressão e exploração da classe oprimida. 0 Estado antigo era acima de tudo, o Estado dos proprietários de escravos para manter subjugados a estes, como o Estado feudal era o órgão da nobreza para dominar os camponeses e os servos, e o moderno Estado representativo é o instrumento de que se serve o capital para explorar o trabalho assalariado. (CARNOY, 1998 p. 69-70 apud ENGELS, 1981, 195-96)

Um Estado desenvolvido que cobre o espaço da produção adequando-se dos papéis privados de gestão e reprodução da força de trabalho, sendo palco de alianças, decorrendo, no limite, o conjunto das relações sociais. De um lado, cobrindo o processo de acumulação por meio de influência, de outro, gerando a regulação da força de trabalho e das relações sociais por meio de uma intensa reforma social. Então, o Estado o Capital e o Trabalho admitiria a declaração de uma esfera de transação triangular, determinando modalidades estruturais novas da luta de classes. Nesta definição, tornou-se provável formar uma combinação entre capital e trabalho aonde, os proprietários dos meios de produção aceitam aos não proprietários a sua organização e a criação dos aparelhos políticos que lhes permitam decretar seus direitos na repartição dos recursos como também, na distribuição de renda. De outro lado, os nãos proprietários dos mecanismos de produção concordam com a sustentação da propriedade privada do capital social e com as normas de lucratividade (LEAL, 1990).

Trazendo essas definições e posição do Estado que é bastante relevante, pois demonstra seu verdadeiro papel, como intermediário entre os capitalistas, os proprietários e os não detentores dos meios de produção. 0 Estado tem que intervir na economia, não deixar o mercado agir sozinho. A mão invisível em que acredita que o próprio mercado se auto regula é uma falácia.

\section{RESULTADOS}

A construção Civil é um forte setor que emprega muita mão-de-obra em Natal/RN, em que a quantidade de empregos formais em 2000 era de 9.282 registros e em 2015 ocorre um aumento para 17.848 pessoas empregadas neste setor. 0 mercado imobiliário na capital do Rio Grande do Norte vem ganhando espaço e mercado. Como Natal é o centro, ou seja, existe uma grande oferta de empresas, as 
pessoas começam a migrar para a cidade de circulação do dinheiro. Então, ocorre uma valorização do solo urbano. Será discutido rapidamente sobre o conceito de solo urbano para melhor entendimento do leitor sobre o espaço no processo capitalista.

Como ilustra Leal (2015) existem empreendimentos que gera grandes impactos na paisagem da cidade. Ela ilustra bem o caso de Recife, mas tudo isso que ela discute, cabe relacionar com Natal. Por exemplo, a mudança do Aeroporto de Parnamirim para São Gonçalo do Amarante, gerou impactos como a valorização dos imóveis, criação de novos empregos e etc. Além de gerar empregos, o aeroporto muda completamente a paisagem onde ele se instalou. As imagens 1 e 2 irão mostrar o antes e o depois da construção do aeroporto. Vale ressaltar o quanto de empregos formais essa construção gerou para a população. Mesmo depois de construído, existe uma quantidade significativa de pessoas trabalhada em tal aeroporto. Além, é claro de valorizar os imóveis localizados nas proximidades.

Figura 1 - Local da construção do aeroporto de Natal

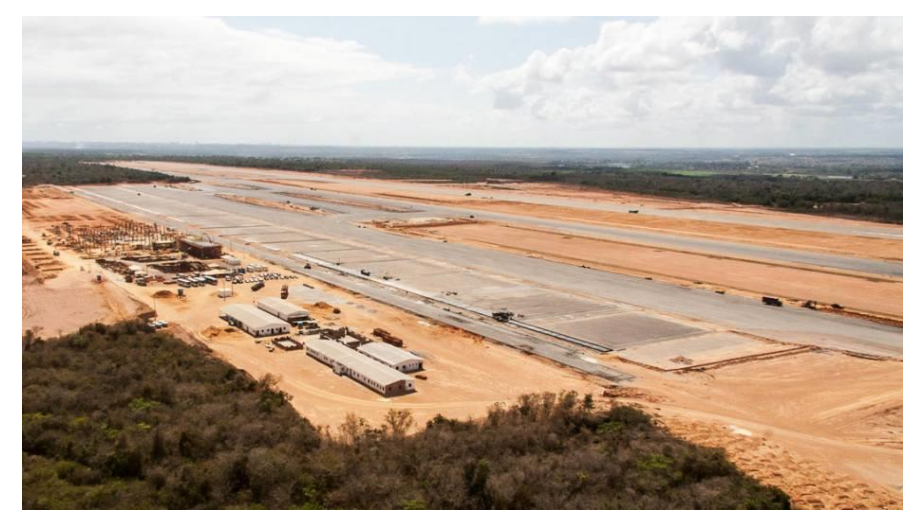

Fonte: Veja.com ${ }^{5}$.

Figura 2 - Aeroporto Internacional Aluízio Alves

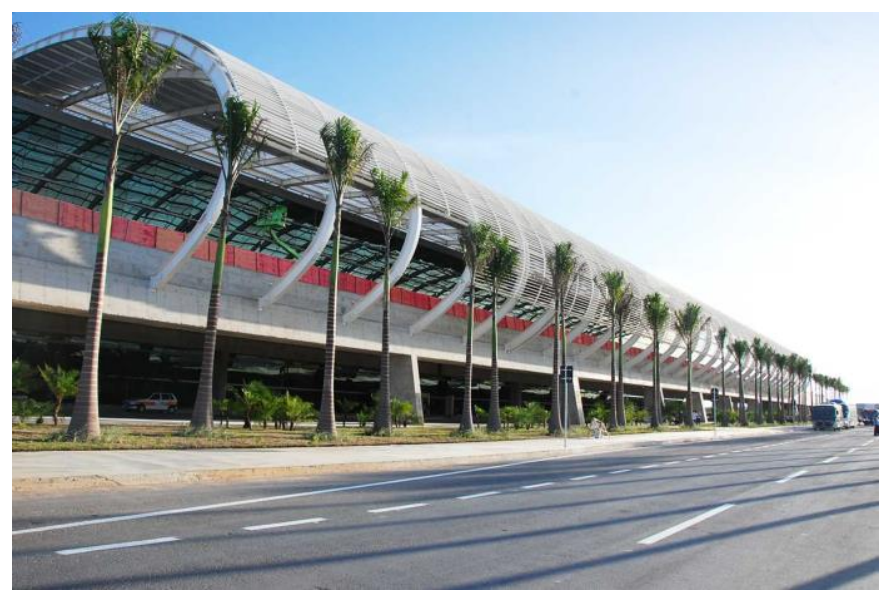

Fonte: Apartamento $702^{6}$.

5 Disponível em: <http://veja.abril.com.br/economia/aeroporto-de-natal-a-15-meses-da-copa-85-da-obra-esta-por-fazer/> Acesso em ago. 2017 
É bastante interessante a mudança na paisagem que um grande empreendimento causa na imagem na cidade, como por exemplo, nosso estudo de caso em Natal-RN. E é isso, que a morfologia urbana quer mostrar os impactos morfológicos. 0 homem tem a capacidade de transformar o lugar onde vive, isso não é apenas de hoje, mas desde a antiguidade. Essa paisagem do aeroporto é uma paisagem excepcional como diriam Di Maio e Berengo. Pois, não é comum encontrar em qualquer lugar. Já uma rua, por exemplo, é uma imagem quotidiana.

A figura 03 e 04 ilustra o Morro do Careca na cidade do Natal, é interessante fazer uma conexão com o que Lamas (2004) chamam de território, que nada mais é, uma extensão da superfície terrestre no qual vivem um grupo de pessoas, ou melhor, é o espaço estabelecido pelo homem, em oposição ao que poderíamos referir por espaço natural e que não tenha ainda sido habitado pelo homem. É o espaço onde o homem desempenha a sua ação, modificando-se as condições físicas, estabelecendo a sua ordem (LAMAS, 2004).

Nas figuras 03 e 04 fica claro o que Lamas escreveu em seu livro: Morfologia Urbana e Desenho da Cidade. 0 morro do careca ao seu redor era inabitado, era um espaço natural. Logo mais, trona-se um espaço habitado, com a construção de casas, edifícios e etc., mas, essas casas e edifícios não são para pessoas de classe média baixa, só consegue residir nessa localidade pessoas com alto poder aquisitivo. Neste caso, as pessoas de baixa renda ficam a margem, um lugar que era de pescadores, agora sendo habitado por pessoas de alto poder aquisitivo, falta para as pessoas que antes residiam nessa localidade o direito a uma moradia digna, pois foram transferidos para outra localidade.

Figura 03 - Morro do Careca no século XX

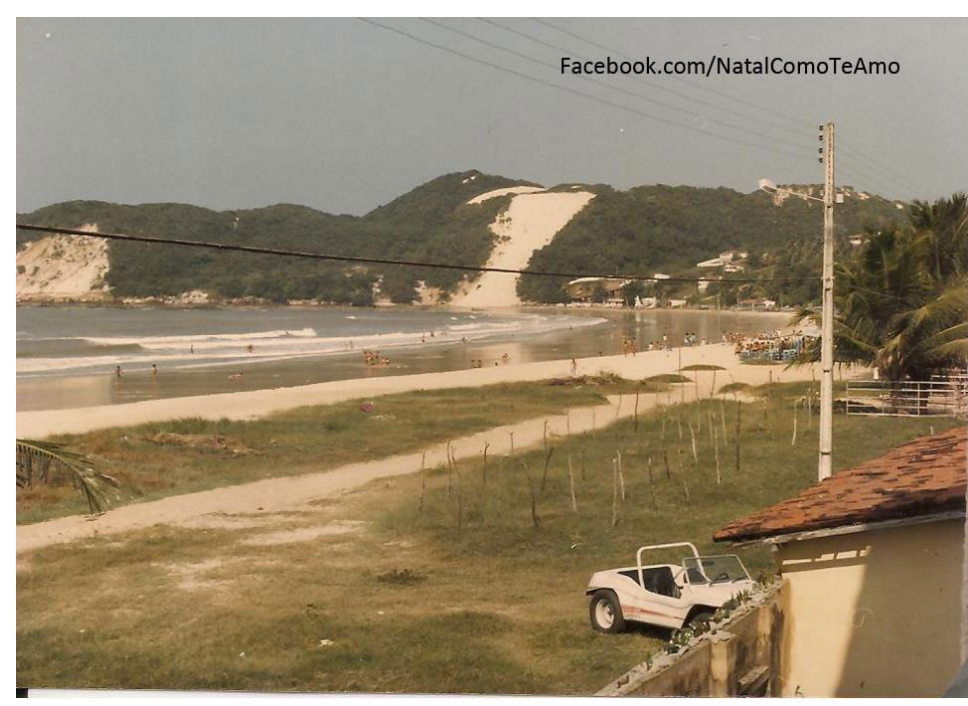

Fonte: Curiozzzo ${ }^{7}$.

\footnotetext{
${ }^{6}$ Disponível em: <https://apartamento702.com.br/saiba-como-chegar-aeroporto-de-natal-pagando-r-250/> Acesso em ago. 2017.

7 Disponível em: <https://curiozzzo.com/2015/07/08/as-20-melhores-fotos-antigas-de-natal-rn-muitas-voce-nunca-viu/> Acesso em ago. 2017.
} 
Figura 04 - Morro do Careca na Atualidade na cidade do Natal

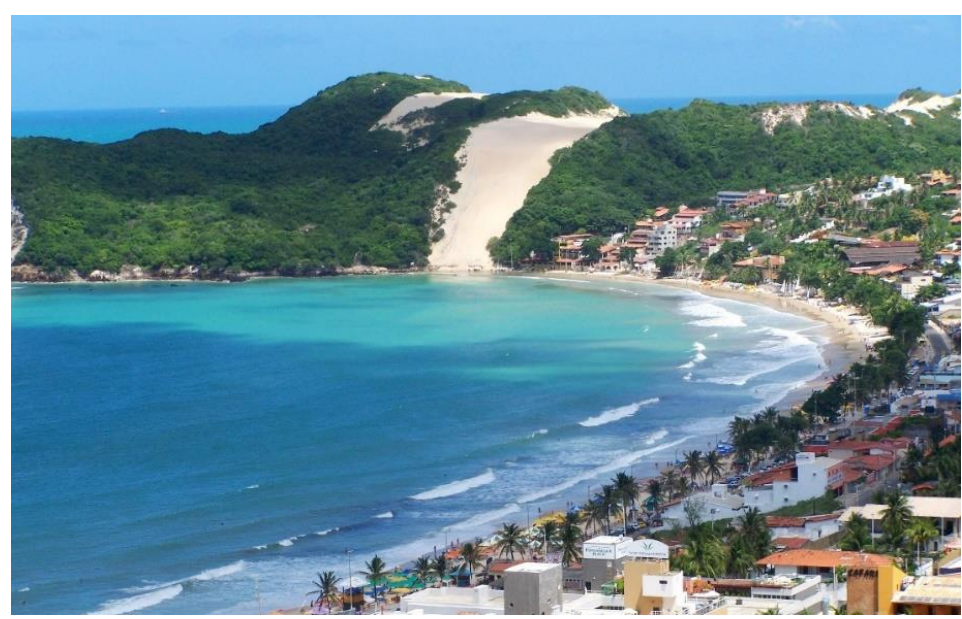

Fonte: DicaNordeste ${ }^{8}$.

A figura 03 e 04 ilustra o morro do careca na cidade do Natal, em que no século passado era praticamente esquecido, apenas os pescadores moravam ao redor. Com o boom do setor imobiliário esses pescadores foram "expulsos" e grandes hotéis, restaurantes e condomínios de luxo foram construídos. Os pescadores ficaram isolados de todo esse luxo, estando fixados em uma pequena vila. Existe o conjunto de Ponta Negra, em que só há casas, hotéis, restaurantes, boates exclusivamente para turistas. Enquanto que as pessoas de renda baixa estão localizadas na vila de Ponta Negra. É interessante o poder que tem o capital, em mudar completamente a conjuntura de uma cidade. Como também transformar a imagem de uma cidade, mas não garante o direito a moradia digna as pessoas que estão a margem, daí entra o papel do Estado, que deveria garantir o direito à moradia da população de baixo poder aquisitivo.

A dinâmica imobiliária por meio do deslocamento das atividades do setor, é referência para compreender as mudanças na estrutura intra-urbana. Então, a ação ligada aos capitais incorporadores retentores do solo urbano e também dos capitais construtores elaboradores da moradia, incidirá na mudança de uso do solo. Pelo meio da transformação do uso, em que os capitais obtêm lucro, e isso os obriga a investirem onde houver possibilidades de transformação, ou seja, o movimento do capital imobiliário é delimitado por uma estrutura espacial pré-existente e pelos valores sobre o ambiente arquitetado futuro. É por meio dessa lógica, que a estruturação intra-urbana e a residencial em particular, tem como atitude decisiva a ação dos capitais imobiliários através da busca de um "Markup" urbano conformando espaços distintos na cidade (ABRAMO; FARIA 1998).

Para realizarem seus ganhos fundiários, o capital imobiliário utiliza estratégias de ação, tais como a atuação de forma concentrada, delimitando áreas de valorização, e a inovação/diferenciação do produto-habitação. Essa inovação não se refere apenas aos atributos do imóvel em si, como altera o padrão de ocupação de toda uma área, valorizando-a em relação às outras áreas da cidade. Essas estratégias se traduzem em

\footnotetext{
${ }_{8}$ Disponível em: <http://dicanordeste.com.br/cinco-lugares-para-visitar-em-natal/> Acesso em ago. 2017.
} 
externalidades, que são incorporadas ao valor dos imóveis, definindo assim, acesso diferenciado das famílias com diferentes rendimentos. Assim, a estratégia de inovação para atrair demanda, se traduz na oferta do bem habitação com todos os seus atributos intrínsecos (características físicas), e extrínseco ("acessibilidades que a localização da moradia permite usufruir"). Esses atributos representam os valores de uso do imóvel, por sua condição essencial de abrigo do homem, como também representa um ativo da economia familiar, e sua aquisição levará em consideração a sua valorização futura na estrutura de preços imobiliários na cidade (Abramo, 1998). A estratégia de inovação da habitação para atrair demanda, serve para diferenciar o novo imóvel do estoque existente, e com isso produz um efeito "depreciador" no estoque, que perde a atratividade anterior, elevando a importância das novas construções (ABRAMO; FARIA, 1998 p. 3).

O que Pedro Abramo chama a atenção na sua citação sobre o mercado imobiliário, trazendo para o presente trabalho, foi o que realmente aconteceu em Natal. Como também nas metrópoles brasileiras.

0 morro do careca é uma paisagem exuberante, atrai muitos turistas. Os restaurantes, hotéis com vista para o morro são bastante apreciados pelos turistas. Nos últimos anos, foi proibida a subida no morro, pois estava destruindo a imagem bela. Em que a areia estava descendo. Daí vale apena ressaltar que a autora Ermínia Maricato (2001), chama de recuperação de áreas consolidadas. Como também é proibido construir casas muito próximas ao morro, pois pode ocorrer um desmoronamento.

A imagem muda com o passar do tempo, ela está sempre em constante mutação, e isso é importante para o estudo morfológico. Daí a importância dos estudos da morfologia urbana. 0 mapa 01 mostra os bairros da cidade do Natal, podemos observar que a parte vermelha quer dizer que o bairro de Ponta Negra é o que mais agrega estabelecimentos, como hotéis, pousadas, condomínios fechados especialmente para turistas, por ser um bairro de turistas.

Segundo as autoras, a paisagem é um texto em contínua transformação. Ela compõe os traços visíveis de uma superfície de terra, pois contêm elementos físicos como o relevo, elementos vivos que fazem parte da flora e da fauna, elementos abstratos como, por exemplo, a luz e as condições meteorológicas e elementos humanos como a atividade humana. Nas palavras de (DI MAIO; BERENGO, 2012 p. 6 e 7):

Se analisarmos tudo o que dissemos até agora, podemos concluir que a paisagem é: Em termos gerais, uma grande superfície formada por elementos naturais (como montanhas, rios e árvores) e elementos humanos (como fábricas e monumentos históricos). É, portanto, uma realidade física que podemos tocar e sobre a qual podemos caminhar. É a visão de uma área com todos os elementos que a natureza criou e alterou e que o ser humano modelou e transformou. Mas, acima de tudo, para cada um de nós, a paisagem é também o sentimento que essa visão provoca (quer se trate de montanhas em flor, duma praia, duma praça com uma velha igreja ou do nosso antigo bairro), uma sensação que faz parte dessa paisagem concreta. Um conjunto de elementos, tanto físicos como imateriais, em contínua mudança. Quando ordenamos alguns objectos de uso quotidiano (como um caneta, um porta-chaves, um vaso, um livro, um telemóvel, uma lâmpada) numa estante ou no nosso escritório, consoante a forma como os colocámos, podemos perceber, além dos objectos em si, também a relação que se estabelece entre eles, por exemplo, as suas cores ou feitios, ou a maneira como estão dispostos. A soma das partes é o que nos faz ver essa estante 
de um modo distinto, como algo que passa de ser um simples portador de objetos para se transformar numa parte integrante do contexto dos objectos que contém. Pois bem, a paisagem é como as diferentes possibilidades de ordenação desses objectos na estante: muda constantemente, tal como a nossa percepção dos seus elementos e do seu todo também muda. Um produto da sociedade. É uma projecção cultural, a partir do ponto de vista material, espiritual, ideológico e simbólico de uma sociedade, sobre um determinado espaço. Um bem que tem um valor inerente. 0 fruto do desenvolvimento e das mudanças contínuas da sociedade, que reflecte a forma de vida de todos os que a vivem e que influencia o seu bemestar, tanto individual como colectivo. A memória do nosso passado e a base para o nosso futuro. Uma espécie de quebra-cabeças, um jogo que consiste num rede de sinais, pistas e pegadas que o explorador, empreendedor duma fabulosa viagem ao longo da sua história, deve descobrir com o seu olhar observador.

Então, estudar a paisagem é algo muito importante e a morfologia urbana faz isso. Ela estuda as formas, as mudanças que a paisagem sofre com o tempo. A cidade sempre está em constante transformação, e o homem é responsável pelas mudanças ocorridas nas cidades. A paisagem está em todo lugar em uma cidade, como exemplo as ruas, é uma paisagem que está em constante transformação, seja para melhor ou pior. Aí vem a importância de um bom planejamento e uma boa gestão.

Mapa 01 - Bairros de Natal com maior concentração de Estabelecimentos.

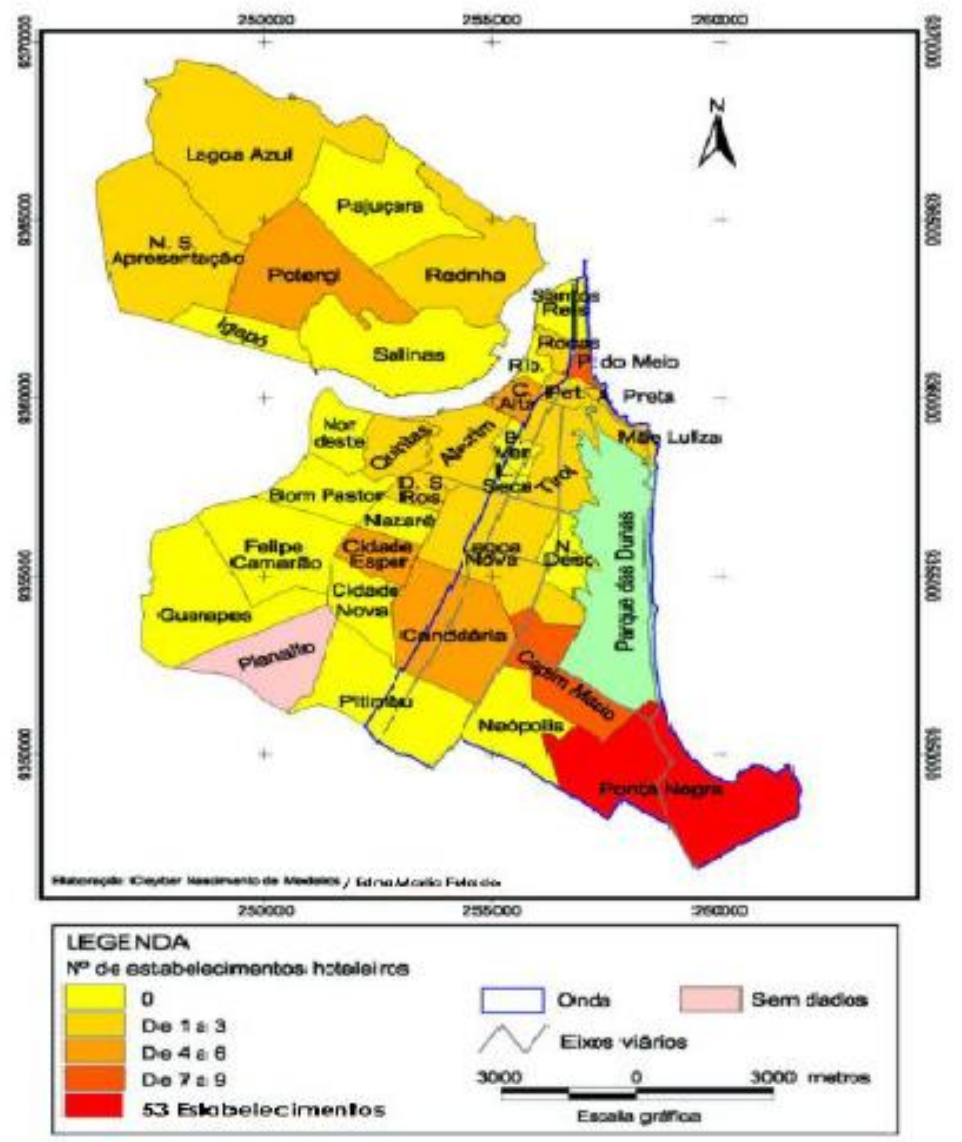

Fonte: (QUEIROZ, 2010 pág. 9) 
Uma cidade em que há bastantes favelas é uma paisagem, mesmo que negativa, mas não deixa de ser uma paisagem. Como já mencionado antes no presente trabalho, o processo de urbanização causa tanto efeitos positivos, quantos efeitos negativos. As favelas são efeitos negativos desse processo que vem ocorrendo nas Regiões Metropolitanas do Brasil, em que o papel do Estado deveria dar uma moradia digna para a população que reside nas comunidades, coisa que não vem ocorrendo com frequência. Em Natal existem muitas favelas, mas são bastante escondidas. Os edifícios "cobrem" digamos essas pessoas que estão à margem. Elas ficam "invisíveis" aos olhos dos turistas.

A autora Ermínia Maricato (2001), chama a atenção para a importância da recuperação de áreas consolidadas, como as favelas por exemplo. Ela cita em seu livro: Brasil, cidades: alternativas para crise urbana página 121 que:

A requalificação ou recuperação de áreas deterioradas implica em considerar o patrimônio público ou privado, já construído, como poupança, num processo de complementação com obras urbanas (urbanização de favelas ou de loteamentos) ou recuperação de edifícios deteriorados (cortiços), ou mesmo de ampliação de moradias existentes. Fazem parte dessa política vários e importantes programas: Urbanização e regularização de favelas; recuperação e prevenção de áreas sujeitas a riscos de desmoronamentos; urbanização e regularização de loteamentos ilegais; reforma e ou ampliação de moradias resultantes do processo de autoconstrução; recuperação de áreas de preservação ambiental ocupadas por moradias; reforma de cortiços e requalificação urbanísticas de áreas centrais degradadas (MARICATO, 2001 pág. 121.)

O combate sobre a cidade ocupada precariamente, ilicitamente, vagarosamente, com insuficientes recursos financeiros e técnicos públicos e privados, não podem dar-se como um conjunto de intercessões preciso segundo (MARICATO, 2001).

Porém, é de grande importância a prevenção de áreas, pois impactos negativos como a favelização pode e muito prejudicar a imagem da cidade. A paisagem deve ser cuidada, preservada de forma que deixe a cidade com um aspecto de perfeição aos olhos das pessoas. Como também, devemse tomar medidas para que as pessoas vivam em constante harmonia com a paisagem. Os governos devem fazer com que as pessoas tenham uma digna moradia, e tentar amenizar os impactos negativos da favelização.

O homem tem o poder de mudar completamente uma paisagem, basta ele querer. As imagens 12 e 13 são a prova disso, mas essa é uma atuação das autoridades para receber um grande evento que irá mudar completamente a cidade aos olhos do mercado internacional. A destruição e construção de um novo estádio trouxeram empregos para o setor da construção civil, várias pessoas foram contratadas para erguer tal monumento. Ocorreram vários debates sobre a construção desse monumento, se seria realmente rentável para a cidade, houve controvérsias. Mas enfim, o objetivo do trabalho não é discutir isso. 
Figura 06 - Antigos estádios da cidade do Natal

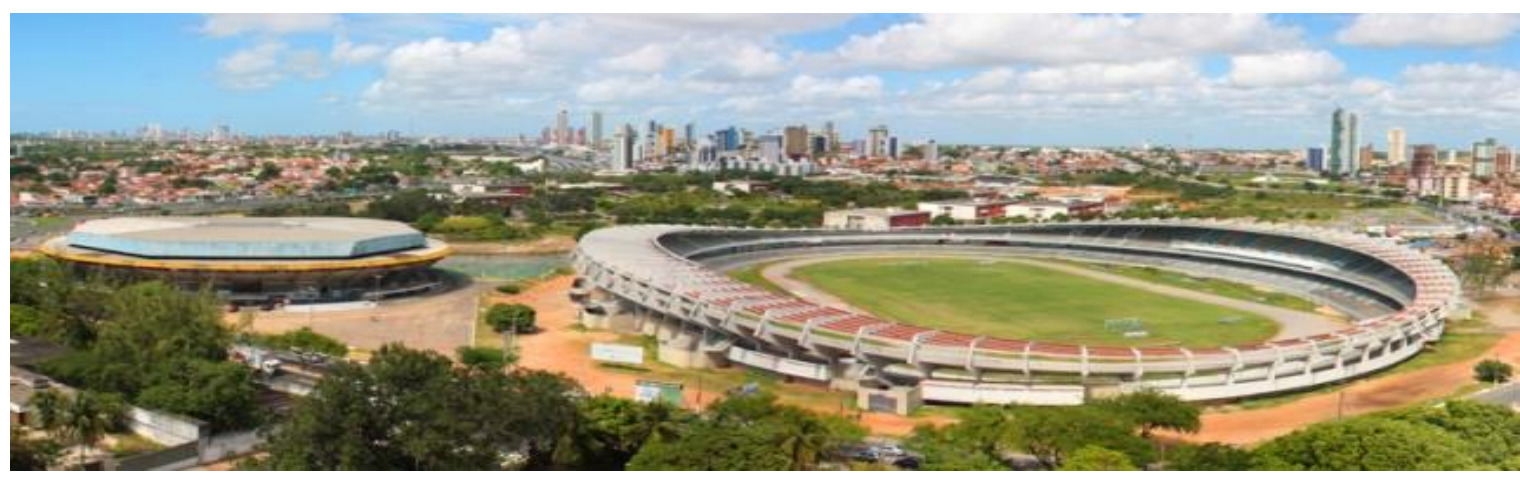

Fonte: Tribuna do Norte. Acesso em: 17/07/2017.

Figura 07 - Atual estádio da cidade do Natal

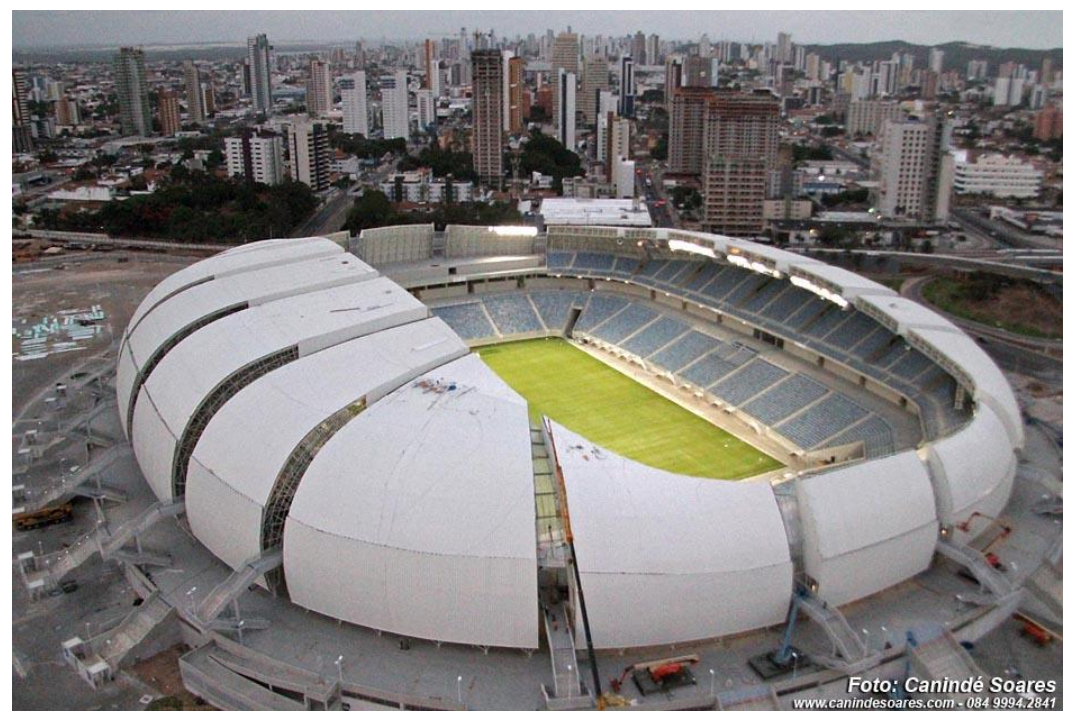

Fonte: Jean Souza ${ }^{9}$.

Como diria Leal (2015) esse estádio é um bom exemplo de um Master Project, que tem como objetivo atrair investimentos estrangeiros e mostrar as cidades para o mercado internacional. Esse novo estádio o Arena das Dunas foi construído para receber um grande evento, a Copa de 2014, realizada no Brasil. Foi preciso destruir o velho estádio, no caso eram dois o Machadão e o Machadinho para poder construir a Arena das Dunas.

Dentre os exemplos de Master Project estão as Cidades e os Bairros Planejados que têm emergido como uma inovação no produto imobiliário, difundindo-se nas áreas periurbanas das metrópoles. Nesse contexto, intervenções físicas de grande impacto, sustentadas por vultosos investimentos públicos e privados, associadas à construção de uma imagem atrativa da cidade para o mercado global, caracterizam um modelo de desenvolvimento apoiado no que David Harvey denomina empreendedorismo urbano (LEAL, 2015 p.5).

\footnotetext{
9 Disponível em: <http://www.jeansouza.com.br/arena-das-dunas/tce-aponta-sobrepreco-em-estruturas-usadas-na-arenadas-dunas-na-copa/> Acesso em ago. 2017.
} 
Esta citação da autora Leal é bastante interessante, pois é o que realmente está acontecendo nas regiões metropolitanas do Brasil. Tanto é que a autora até cita que David Harvey já analisava isso, esse empreendedorismo urbano. Os Martes Project tem essa finalidade, atrair investimentos e servir de vitrine para o mercado global.

As legendas Cidades Planejadas e Cidades Inteligentes é uma forma de marketing para as grandes empresas para comerciarem seus produtos imobiliários, como também, termos de um novo formato de Convenção Urbana e de Governança Corporativa. As inovações na tipologia e morfologia dessas novas Cidades Planejadas são os megaempreendimentos em espaços loteados e privados para a construção de cidades dentro de cidades, aglomerando em um só local. Como por exemplo, os shoppings, hotéis, hospitais, escolas, imóveis residenciais, lojas comerciais, entre outros (LEAL, 2015).

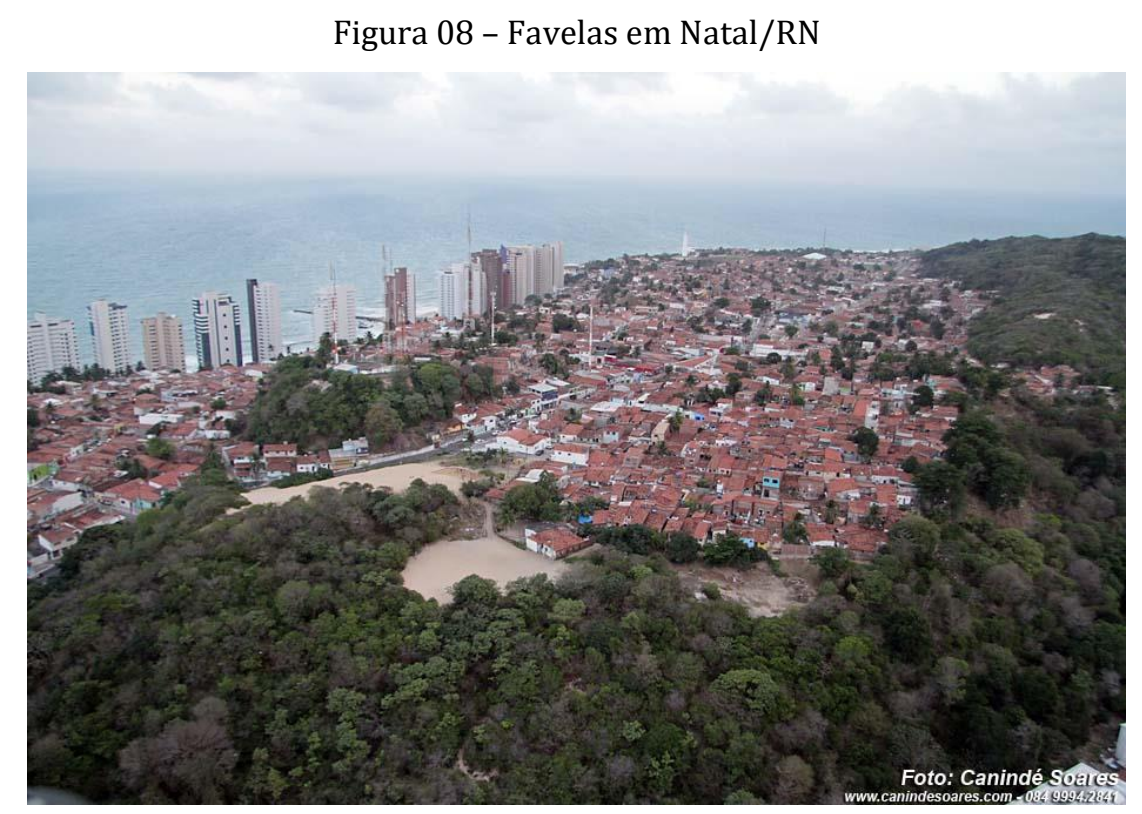

Fonte: Canindé Soares.

Isso tem sua importância, pois gera mais empregos para a população. Com isso, aumenta o processo de urbanização. Havendo o lado positivo, que é o aumento de empregos. Como também, o lado negativo, a favelização, em que as pessoas que residem nessa localidade não possuem uma boa qualidade de vida, como saneamento básico acesso aos transportes etc. a figura 08 ilustra uma comunidade "excluída" e em sua frente prédios de luxo. Aí entra a questão do direito a cidade, essas pessoas que estão à margem será que possuem boas condições de vida? É bastante pertinente pensar o direito de moradia dessa população.

A figura 09 mostra o bairro das quintas, um bairro que é considerado marginalizado, ou seja, está à margem das populações de classe alta. A figura 10 ilustra melhor as condições de moradia dessa população, que não são boas. 
Figura 09 - comunidade das Quintas

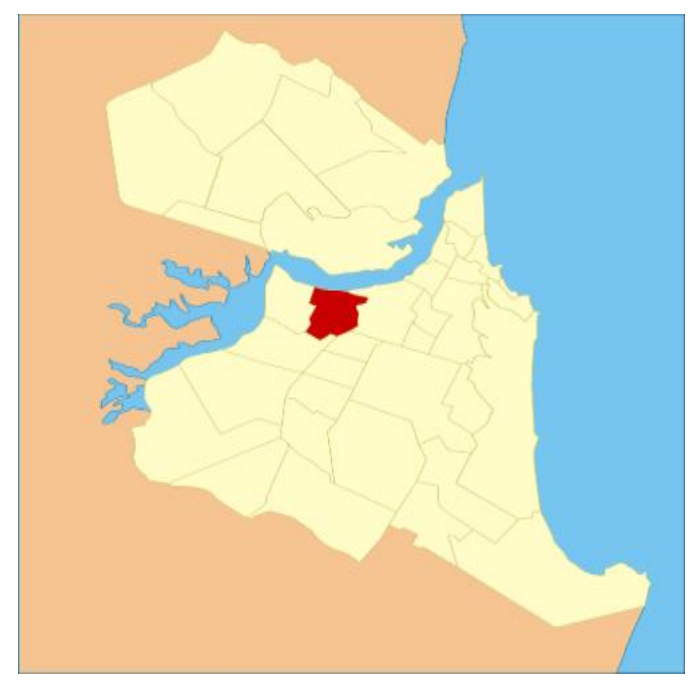

Fonte: Canindé Soares.

Figura 10 - Comunidade das Quintas

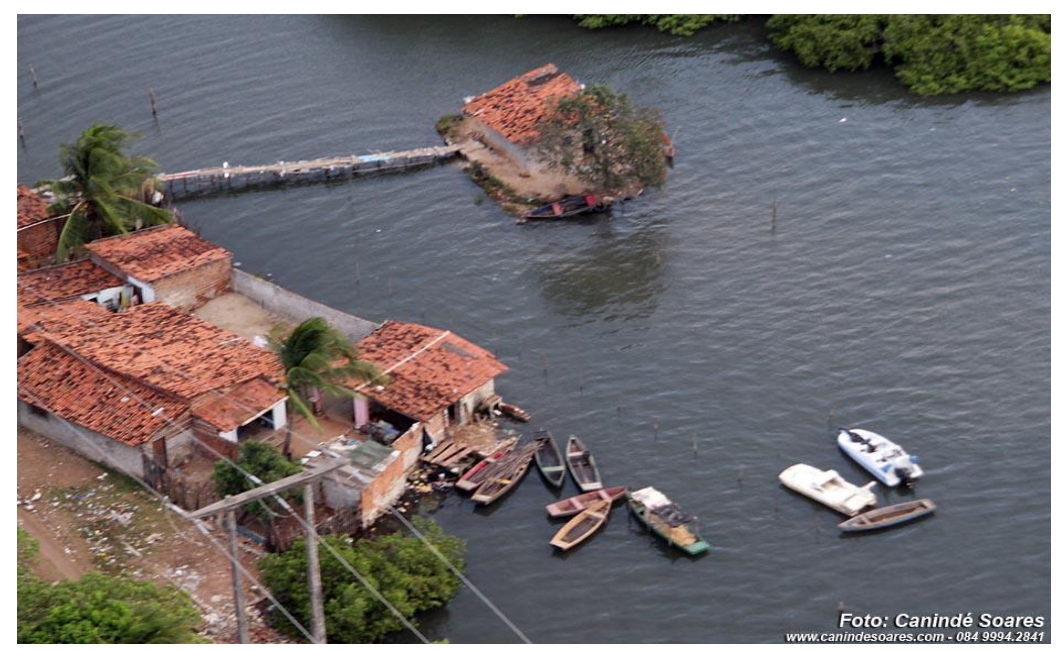

Fonte: Canindé Soares.

Em linhas gerais o direito à cidade, defendido por Lefebvre, se confunde com o próprio direito à vida, e por isso mesmo independe de seu reconhecimento como membro "natural" ou não de certo espaço. $\mathrm{O}$ autor reivindica uma integral cidadania a todos os habitantes de uma determinada cidade, seja ela qual for, sendo este reconhecimento formal ou não formal (LEFÈVRE, 2001).

\section{CONSIDERAÇÕES FINAIS}

O presente trabalho trouxe como estudo de caso a cidade do Natal/RN como estudo do processo capitalista do espaço urbano e o direito á cidade. Em alguns bairros da cidade do Natal, a produção imobiliária é cada vez mais perceptível. A população carente da cidade, em sua ocupação 
desordenada, é progressivamente lançada para áreas mais distantes deste crescimento urbano, promovido pela indústria imobiliária. Os Arranjos institucionais que deveriam fortalecer as políticas urbanas em favor de moradias populares, são postos de lado por causa dos interesses difusos e particulares, que não favorecem ao coletivo. Ou seja, essas relações focam tem como foco as ações prómercado com objetivos específicos e integrados a lógica do capital globalizado, deixando parte, normalmente a mais pobre, da sociedade civil fora do processo.

Outro fator identificado, é que a cidade de Natal tem sido planejada de forma que às áreas mais carentes não ficam evidentes no trajeto turístico que é desenvolvido para "urbe". Outra característica voltada ao mercado que não se preocupa com o planejamento urbano-regional de uma cidade, mas sim com a lógica de acumulação, por este fato, boa parte da sociedade civil pobre não participa do trajeto turístico, pois essas localidades "não devem ser vistas" perante a hegemonia do capital especulativo que objetiva, apenas, na valorização das terras urbanas sem se preocupar com as necessidades da totalidade sociedade civil da cidade de Natal.

Esta situação proporciona uma cidade planejada pró-mercado a partir da lógica do empreendedorismo urbano munido pelo planejamento estratégico em que o turista não ver as favelas, só as "belezas" da cidade de Natal. Em resumo, uma boa parte da população que vive em situações precárias nos diversos bairros de Natal não possuem saneamento, transporte público adequado ou mesmo estrutura de moradia, mas essa situação, normalmente, não faz parte da preocupação do gestor público (o prefeito, secretários, vereadores, entre outros), pois como apresentado em todo artigo o grande foco atualmente é com o planejamento estratégico da cidade de Natal e nessa lógica a necessidade é de mostra que ela é um grande artigo de luxo, tendo como objetivo a "venda" de um imaginário da cidade global, mesmo ela não estando em um patamar das grandes cidade globais.

Portanto, e finalizando para dar uma boa qualidade de vida para as populações que residem em áreas vulneráveis, o Estado precisa intervir de forma mais efetiva e igualitária no espaço urbano e sua apropriação, pois o direito à cidade deve ser para todos e não para quem pode pagar ou para alguns agentes específicos. Nos bairros nobres ficam: às belezas, as riquezas e o turismo, enquanto que, a outra parte da população, está à margem de tudo, ou seja, fora da realidade globalizada dentro de uma lógica de um espaço opaco sem oportunidade se desenvolver na cidade em que vive que neste caso específico é a cidade de Natal.

\section{REFERÊNCIAS}

ABRAM0, Pedro. Regulação Urbana e o Regime Urbano: A Estrutura Urbana, Sua Reprodutibilidade e o Capital. Ensaios FEE, Porto Alegre, 1995.

ABRAMO, Pedro; FARIA, Teresa Cristina. Mobilidade Residencial $\mathrm{Na}$ Cidade Do Rio De Janeiro: Considerações Sobre Os Setores Formal E Informal
Do Mercado Imobiliário. XI Encontro Nacional de Estudos Populacionais da ABEP. São Paulo. 1998. BARBOSA, Adauto Gomes; COSTA, Ademir Araújo da. 0 solo urbano e a apropriação da natureza na cidade. Soc. \& Nat., Uberlândia, ano 24 n. 3, 477488, set/dez. 2012. 
CARNOY, Martin. Estado e Teoria política. (equipe de trad. PUCCAMP) 2 $2^{\text {a }}$ ed. Campinas: Papirus, 1988. [pp. 19-62]

CARLOS, Ana Fani Alessandri. O Espaço Urbano: Novos Escritos sobre a Cidade. São Paulo: FFLCH, 2007, 123p.

CLEMENTINO, Maria do Livramento; et. al. Natal: Transformações na ordem urbana. Letra Capital Editora. Observatório das Metrópoles, Natal, 2015.

DI MAIO, Sara. BERENGO, Cecilia. Nós somos a Paisagem: Como interpretar a Convenção Europeia da Paisagem. Tradução adaptada versão portuguesa (C) MAPa 2012. Em colaboração com Riccardo Priore e Damiano Gallà.

FREITAS; Tânia Maria de; FERREIRA, Cleison Leite. A produção do espaço urbano: formação de território e governança urbana, o caso da quadra 50 da cidade Gama - DF. Anais do I Circuito de Debates Acadêmicos. CODE/IPEA. Brasília, 2011.

FULGÊNCIO, Vinícius Albuquerque. Gestão Metropolitana e Autonomia Municipal: O caso da Região Metropolitana do Recife. Dissertação apresentada à Coordenação do Programa de PósGraduação em Desenvolvimento Urbano, da Universidade Federal de Pernambuco. Recife, 2015.

GONZÁLEZ, Samuel Jaramilho. Hacia uma teoria de la rendadel suelo urbano/Samuel Jaramilho Gonzaléz - 2a ed- Bogotá Universidad de los Andes Faculdad de economia, CEDE edcionesUniandes, 2010.

HARVEY, David. Condição pós-moderna. Vol. 2. Edições Loyola, 1994.

O direito à cidade. Lutas Sociais, São Paulo, n.29, p.73-89, jul./dez. 2012.

A produção capitalista do espaço. São Paulo: Annablume, 2005.

LAMAS, José Manuel Ressano Garcia. Morfologia Urbana e desenho da cidade. 3a edição. [Lisboa]: Fundação Calouste Gulbekian, 2004.

LEAL, Suely Maria Ribeiro. As veias abertas do planejamento urbano e a avalanche da governança do mercado. Miolo - Desenvolvimento, planejamento e governança. Rio de Janeiro: Letra Capital/ANPUR, 2015.

LEAL, Suely Maria Ribeiro. "A outra face da crise de Bem-Estar Social: Neoliberalismo e os novos movimentos da sociedade do trabalho". Universidade Estadual de Campinas Núcleo de Estudos de Política - NEPP Campinas, fevereiro 1990.

LEFÈVRE, Henri. $O$ direito à cidade. Tradução Rubens Eduardo Frias. São Paulo: Centauro Editora, 2001.

MARICATO, Ermínia. Brasil, Cidades: Alternativas para a crise urbana. Editora Vozes Ltda. Petrópolis, RJ, 2001.
MARX, Karl. O capital. Crítica da economia política. São Paulo, Abril Cultural, 1983.

PESSOA, Zoraide Souza. Uma análise do Movimento Pendular na definição da Espacialidade Territorial e Social Na RMNatal. XI Encontro da Associação Nacional de Pós-graduação e Pesquisa em Planejamento Urbano e Regional - ANPUR. Salvador (BA) 2005.

QUEIROZ, Thiago Augusto Nogueira de. A PRODUÇÃO DO ESPAÇO URBANO DE NATAL/RN: Algumas Considerações Sobre as Políticas Públicas OBSERVATORIUM: Revista Eletrônica de Geografia, v.2, n.4, p.2-16, jul. 2010.

SANTOS JÚNIOR, Orlando Alves dos. A Produção Capitalista do Espaço E os Conflitos Urbanos. 1. ed. - Rio de Janeiro: Letra Capital, 2017.

SANTOS, Orlando Alves dos. Políticas públicas $e$ direito à cidade: programa interdisciplinar de formação de agentes sociais / organização Orlando Alves dos Santos Junior ... [et al.]. - 1. ed. Rio de Janeiro: Letra Capital, 2017. 142 p.

SILVA, Oséias Teixeira da. Renda Fundiária ou valor da terra? Aportes sobre o debate em torno da produção do Espaço Urbano. Caderno Prudentino de Geografia, Presidente Prudente, n.34, v.1, p.97116, jan./jul.2012.

SILVA, Regina Celly Nogueira da; MÂCEDO, Celênia de Souto. A produção do espaço urbano. Programa Universidade à Distância (UNIDIS). Disciplina Geografia Urbana do curso de geografia da UFRN e UEPB. 